Prepared for the U.S. Department of Energy

under Contract DE-AC05-76RL01830

\title{
Multiscale Toxicology- Building the Next Generation Tools for Toxicology
}

PNNL Final Report

BD Thrall (Lead) JG Teeguarden

KR Minard KM Waters

September 2012

Pacific Northwest

NATIONAL LABORATORY

Proudly Operated by Battelle Since 1965 


\title{
DISCLAIMER
}

This report was prepared as an account of work sponsored by an agency of the United States Government. Neither the United States Government nor any agency thereof, nor Battelle Memorial Institute, nor any of their employees, makes any warranty, express or implied, or assumes any legal liability or responsibility for the accuracy, completeness, or usefulness of any information, apparatus, product, or process disclosed, or represents that its use would not infringe privately owned rights. Reference herein to any specific commercial product, process, or service by trade name, trademark, manufacturer, or otherwise does not necessarily constitute or imply its endorsement, recommendation, or favoring by the United States Government or any agency thereof, or Battelle Memorial Institute. The views and opinions of authors expressed herein do not necessarily state or reflect those of the United States Government or any agency thereof.

\author{
PACIFIC NORTHWEST NATIONAL LABORATORY \\ operated by \\ BATTELLE \\ for the \\ UNITED STATES DEPARTMENT OF ENERGY \\ under Contract DE-AC05-76RL01830
}

Printed in the United States of America
Available to DOE and DOE contractors from the Office of Scientific and Technical Information,
P.O. Box 62, Oak Ridge, TN 37831-0062;
ph: (865) 576-8401
fax: $(865)$ 576-5728
email: reports@adonis.osti.gov

\begin{abstract}
Available to the public from the National Technical Information Service, U.S. Department of Commerce, 5285 Port Royal Rd., Springfield, VA 22161 ph: (800) 553-6847 fax: $(703) 605-6900$ email: orders@ntis.fedworld.gov online ordering: http://www.ntis.gov/ordering.htm
\end{abstract}

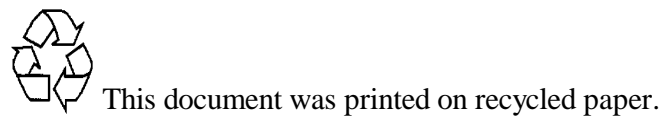




\section{Abstract}

A Cooperative Research and Development Agreement (CRADA) was sponsored by Battelle Memorial Institute (Battelle, Columbus), to initiate a collaborative research program across multiple Department of Energy (DOE) National Laboratories aimed at developing a suite of new capabilities for predictive toxicology. Predicting the potential toxicity of emerging classes of engineered nanomaterials was chosen as one of two focusing problems for this program. PNNL's focus toward this broader goal was to refine and apply experimental and computational tools needed to provide quantitative understanding of nanoparticle dosimetry for in vitro cell culture systems, which is necessary for comparative risk estimates for different nanomaterials or biological systems. Research conducted using lung epithelial and macrophage cell models successfully adapted magnetic particle detection and fluorescent microscopy technologies to quantify uptake of various forms of engineered nanoparticles, and provided experimental constraints and test datasets for benchmark comparison against results obtained using an in vitro computational dosimetry model, termed the ISSD model. The experimental and computational approaches developed were used to demonstrate how cell dosimetry is applied to aid in interpretation of genomic studies of nanoparticle-mediated biological responses in model cell culture systems. The combined experimental and theoretical approach provides a highly quantitative framework for evaluating relationships between biocompatibility of nanoparticles and their physical form in a controlled manner. 


\section{OBJECTIVE}

A Cooperative Research and Development Agreement (CRADA) was initiated in FY2010, sponsored by Battelle Memorial Institute (Battelle, Columbus), to initiate a multi-DOE National Laboratory collaborative research program aimed at developing a suite of new capabilities for predictive toxicology and safety assessment. Assessing potential safety/toxicity of nanomaterials was chosen as one of two focusing problems (research tracks) for this program, with the second track focused on predicting toxicity of cardiovascular drugs. Partnering laboratories involved include the Lawrence Livermore National Laboratory (LLNL), Pacific Northwest National Laboratory (PNNL), Oak Ridge National Laboratory (ORNL), Brookhaven National Laboratory (BNL) and Battelle. PNNL's contribution to the project was focused on the nanoparticle toxicology track of the program.

Engineered nanomaterials are expected to play a major role in energy production, use and storage for the future, as evident by DOE's multi-million dollar investments in Nanotechnology Centers at several of the National Labs. With an increased production and use of these materials now and in the future, there is concern that there will be increased likelihood of occupational exposures. The benefits of this program to each National Laboratory, including PNNL and DOE, is the development of new tools for providing insights into the safety of these next generation materials and technologies intended for use in energy production and use. In addition, as nanotechnology progresses, understanding of the biological effects of these materials may become important in development of countermeasures against biosecurity threats. Engineered nanomaterials are currently being developed and used in humans for a variety of pharmaceutical and medical diagnostic applications. Thus, the anticipated benefits of this program to Battelle also includes demonstrating expertise in nanotechnology as it applies to medical technologies, and transfer of technology and/or capabilities developed at the National Laboratories in support of health risk-related research and testing to its private and government sector clients.

This cooperative relationship combines unique National Laboratory resources and measurement capabilities with Battelle's expertise in basic and translational health research. The longer term objectives of the program are to combine existing measurement capabilities into a unique multiscale toxicology assessment pipeline, to integrate data from different end-point studies into a comprehensive model that links the in vitro cellular effects to the in vivo whole animal response and most importantly to develop a suite of new capabilities that, when combined, will add new insights into the potential toxicities of nanomaterials developed for use in humans, or by which humans may be exposed occupationally. Such insights should reduce the time it takes to complete safety assessments and thus reduce the time it takes to make new products and nanoenabled technologies available to the public. Importantly, the end products of this research will be of similar value for assessing the safety of chemical agents used in commerce as well as those found in the environment.

\section{Goals and Expected Outcomes.}

The overall goal of this program is to conduct research needed to develop a toxicity testing pipeline using quantitative techniques and next generation tools that combines insights into the molecular mechanisms responsible for the toxicity of nanomaterials and to what cells and organs 
are affected. This includes development and application of a group of quantitative techniques that measure molecular, cellular, organ and whole organism dose and responses to a point where toxicity can be related to the properties of the materials. The capabilities developed cooperatively by Battelle and the participating National Labs will provide the basis for a broadlyapplicable set of analytical tools that will eventually lead to the next generation of safety testing techniques.

PNNL's tasks under this CRADA were designated by Battelle program leadership and were based on the existing expertise in nanotoxicology at PNNL. Only activities performed by PNNL are summarized in this final report. Specifically, the research tasks for which PNNL was the lead laboratory focused on dosimetry measurement and modeling for cell culture studies, including:

a) Coordinate the development of experimental protocols, cell exposure and screening assays with the other partners of this program;

b) Establish capabilities to assess cellular dosimetry and quantify how cells respond to nanoparticle exposure;

c) Conduct targeted live cell imaging and other measures as necessary to quantify of the uptake of nanoparticles in cells;

d) Develop bioinformatics strategies to describe biological responses and biological pathways affected by nanoparticle exposure.

The overarching deliverables expected from these tasks included: a) developing new information on the cellular targets responsible for the toxicities of specific nanoparticles and b) demonstrating the feasibility of a new toxicity testing paradigm based on quantitation of cellular and molecular endpoints. In keeping with the fundamental research nature of the program and National Laboratory participants, the primary measures of these deliverables are scientific presentations, publications and where appropriate, technology transfer.

\section{General Approach}

A primary focus of PNNL's effort was to refine and apply tools needed to provide quantitative understanding of nanoparticle dosimetry (dose to the target cell) for in vitro cell culture systems, which is necessary for comparative risk estimates for different nanomaterials or biological systems. Given the most likely scenario for occupational exposure to engineered nanomaterials is through inhalation, represent lung cells were chosen as model systems for investigation in these studies. These included a mouse lung epithelial cell line (C10) and a mouse macrophage cell line (RAW 264.7). For some studies, mutants of the RAW 264.7 cell line which lack scavenger receptors involved in uptake of nanoparticles (previously developed at PNNL) were used for comparison. For model nanoparticles, superparamagnetic iron oxide and amorphous silica nanoparticles, ranging from $15-33 \mathrm{~nm}$ core sizes, were obtained commercially (Ocean Nanotech) or prepared and supplied by ORNL (prepared "in-house”). In addition, commercial sources of fluorescent polystyrene were used.

Cell dosimetry measurements were obtained by fluorescent microscopy of labeled polystyrene nanoparticles as well as by adapting a magnetic resonance-related technique constructed at PNNL for cell culture studies. Magnetic particle detection (MPD) specifically exploits the nonlinearity of nanoparticle magnetization (Krause et al. 2007) and has been successfully used for sensitive immunoassays as well as for real-time monitoring of nanoparticle kinetics in 
circulating blood (Nikitin et al. 2008). For the current work, MPD instrumentation was adapted for use in cell culture studies to measure total cell associated dose of superparamagnetic nanoparticles following exposure in vitro. These data, along with existing data available at PNNL and literature data where appropriate, were used to provide experimental constraints and test datasets for benchmark comparison against results obtained using an in vitro dosimetry model, termed the In vitro Sedimentation and Diffusion Dosimetry Model (ISSD). ISSD calculates transport and delivery of nanoparticles, based on first principals of gravitation and diffusion, given known parameters for cell culture conditions such as media volume, height, viscosity, etc. A full description of the ISSD model is provided in Hinderliter et al. (2010).

The biological response of cells exposed to nanoparticles was determined by genomic analysis of gene expression patterns using Affymetrix microarrays and quantitative reverse transcription polymerase chain reaction (qRT-PCR) assays. Affymetrix analysis was conducted at Battelle from total RNA samples prepared at PNNL. qRT-PCR and bioinformatics analyses of gene expression was conducted at PNNL, using standard approaches previously developed (Waters et al. 2009).

\section{Results and Outcomes}

For summary purposes, only examples of key results and outcomes of the tasks led by PNNL are provided below for illustration. A full list of scientific presentations and publications arising from work conducted at PNNL are provided at the end of this section.

4.1. Adaption of MPD for Cell Dosimetry. A simple low-cost inductive sensor developed at PNNL was adapted and applied in these studies to quickly determining the total mass of magnetic nanoparticles that is bound to the plasma membrane and internalized by cultured cells. MPD sensor operation exploits an oscillating magnetic field $\left(f_{0}=250 \mathrm{kHz}\right)$ together with the nonlinear response of particle magnetization to generate a harmonic signal $\left(f_{3}=750 \mathrm{kHz}\right)$ that varies linearly with particulate mass $\left(\mathrm{R}^{2}>0.999\right)$ and was found to be sufficiently sensitive for detecting $100 \mathrm{ng}$ of carboxyl-coated iron-oxide nanoparticles in under a second. When exploited for measuring receptor-mediated nanoparticle uptake in RAW 264.7 macrophages, results showed that the achieved dosimetry performance was comparable with relatively expensive analytical techniques that are much more time-consuming and labor-intensive to perform. Examples results obtained with MPD are illustrated below (Minard et al., manuscript submitted).
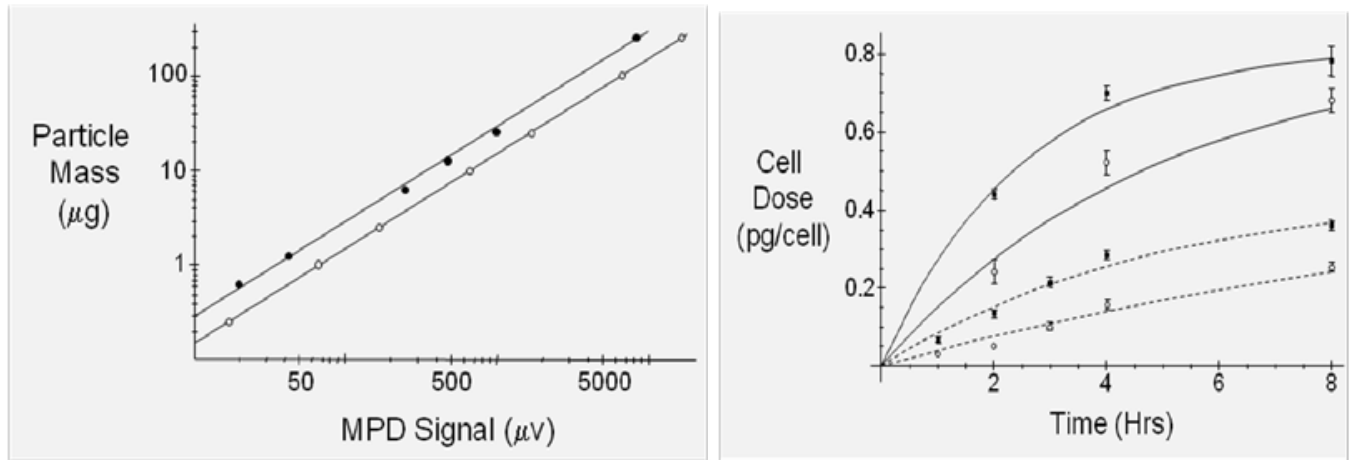

Figure 1: Left: MPD Sensor calibration and linearity. The known mass of Ocean NanoTech $(\mathbf{O})$ and in-house $(\mathbf{O})$ iron oxide nanoparticles in calibration standards is plotted as a function of sensor output voltage. Data is well fit $\left(\mathrm{R}^{2} \geq 0.9996\right)$ to a 
straight line that has zero intercept and a slope that defines detection sensitivity. Right: Cell nanoparticle dosimetry. Average cell doses for wildtype $(\mathbf{G})$ and SR-A deficient macrophages $(\mathbf{O})$ are shown with error bars that represent standard deviations from three replicates. Numerical fitting to Eq. 1 summarizes time-dependent results during exposure to either Ocean NanoTech (_) or in-house nanoparticles (- - - $)$.

4.2. Comparison of MPD Experimental Results and ISSD Dosimetry Modeling. Transport of the polydisperse solution of iron oxide nanoparticle agglomerates to cells grown as a monolayer in liquid culture was modeled as a mass weighted distribution of particles in accordance with the particle size and number fraction associated with each agglomerate size class, as determined by dynamic light scattering. The total mass of iron oxide delivered at each time step was calculated as the sum of calculated mass (fraction delivered times mass in the experiment) of each of the five agglomerate particle size classes delivered. The fractal dimension (DF) of the iron oxide agglomerates was not known. Improbable values of DF, 1 (representing a rod) and 3 (representing a perfectly filled sphere) were not considered. Values near those reported in the literature for cerium oxide and fumed silicon dioxide of $~ 2.0$ were considered plausible. Accordingly, DF was varied between 2.0 and 2.4, to evaluate model behavior against the experimental data. For this range of plausible values of DF, ISDD calculated delivered iron oxide was in close agreement with measured values of cell associated iron oxide (Figure 2), differing at most by a factor of approximately 2 or less. Correspondence between observed and model calculated transport of iron oxide was greatest, differing by only 5-30\%, for a DF of 2.3. Thus, overall good agreement between experimental and model estimates of delivered dose to cells was obtained.

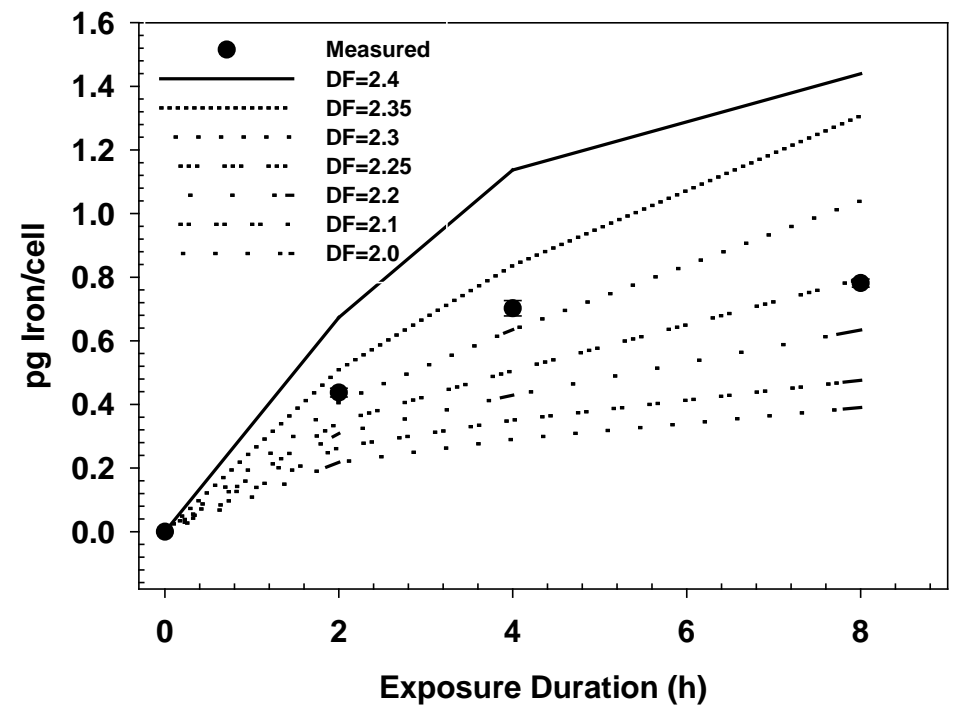

Figure 2. Simulated Transport of Iron Oxide Agglomerates. Comparison of the modeled and observed transport kinetics of iron oxide agglomerates to RAW 264.7 macrophages. Particle transport was modeled for plausible values of the agglomerate fractal dimension (DF); a DF of 2.3 provided the best correspondence between modeled and observed data. Error bars (visible only on one point) for experimental data reflect standard deviations. The media height was $1.06 \mathrm{~mm}$ in this experiment.

4.3. Integrated Dosimetry and Gene Expression Analyses. The dosimetry measurement and modeling capabilities developed in this work provided a means to directly compare toxicological 
potencies of different types of particles based on actual cell doses, rather than simply concentration of particle in the culture medium. As illustrated in Figure 3, we applied these approaches to also evaluate the effect that nanoparticle agglomeration has on cellular responses. Aggomeration of nanoparticles is a common phenomena that occurs in most culture systems, and can introduce challenges in interpreting in vitro toxicology data. Using the approaches described, along with methods to produced agglomerates of iron oxide nanoparticles of controlled size, we demonstrated that nanoparticle agglomeration state significantly influences the amount of dose delivered to cells in culture, and affects their potential to induce cytotoxicity, oxidative stress and gene expression. When compared on a delivered total nanoparticle mass/cell dose metric basis, measured by MPD, small agglomerates were found to induce greater oxidative stress, cytotoxicity and redox-regulated gene expression compared to large agglomerates. These differences were not apparent when responses were evaluated as a function of media concentration ( $\mu \mathrm{g} / \mathrm{ml}$ of nanoparticle) alone. Theoretical calculations using the ISDD model on agglomerate surface area revealed that the biological response normalizes when cells are exposed to equivalent total delivered nanoparticle surface area irrespective of agglomerate diameter, suggesting surface accessible iron oxide molecules are responsible for catalyzing the oxidative stress response. The combined experimental/theoretical approach thereby provides a highly quantitative framework for evaluating relationships between biocompatibility of NPs and their physical form in a controlled manner.
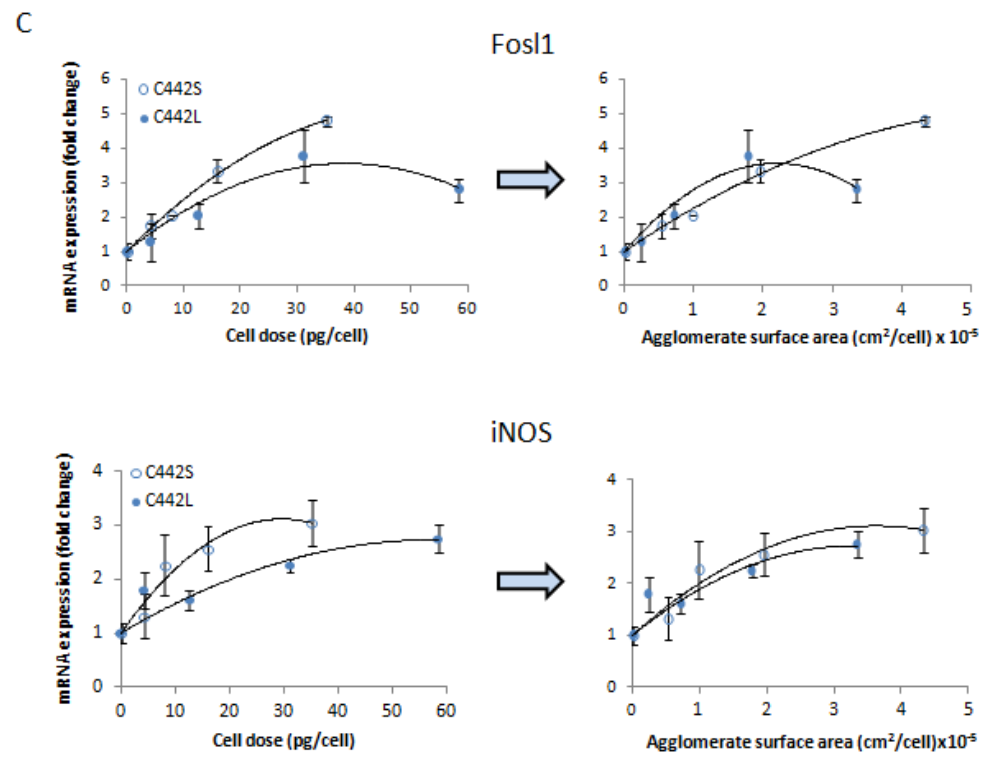

Figure 3. Oxidative Stress Mediated Gene Expression. Results shown dose-response relationships for two oxidative stressregulated genes in C10 epithelial exposed following exposure to either small (C442S, $276 \mathrm{~nm})$ or large (C442L, 689 nm) agglomerates of iron oxide nanoparticles, composed of identical primary particles ( $33 \mathrm{~nm}$ diameter). For comparison, the dose is expressed in either mass/cell (pg/cell), or the amount of agglomerate surface area delivered to the cells. Agglomerate surface area was calculated using fractal dimension (DF) values for agglomerates as identified from ISDD simulations. On a surface area metric basis, the biological response of small and large agglomerates of carboxy-modified nanoparticles was found to give similar dose-response profiles. Results are from Sharma et al. (manuscript submitted). 


\section{Summary of Outcomes}

As illustrated in these example results, PNNL successfully adapted and developed new strategies to incorporate cell dosimetry for engineered nanomaterials into in vitro systems for toxicological hazard analysis and testing. The studies performed were presented at major scientific meetings and invited presentations made by PNNL staff at national conferences, and contributed to several peer-reviewed publications. As demonstrating scientific leadership in nanotoxicology was an initial expected outcome of the program, the consensus from Battelle program leadership was that PNNL tasks were successfully completed and contributed positively to this outcome.

An assessment of the market potential for toxicological testing of nanomaterials with large pharmaceutical companies was conducted by Battelle in FY2011-2012. Based on the outcome of this market assessment, Battelle chose in FY2012 to shift its focus from the nanotoxicology track of the CRADA, and focus the program resources on issues of predicting cardiovascular drug toxicities. The consensus from Battelle program leadership was that the PNNL research tasks were sufficiently complete with submission of manuscripts for publication. Manuscripts published or submitted, along with other presentations and invited presentations made by PNNL contributors from work are provided below (data from PNNL ERICA database):

\subsection{Abstracts and Conference Presentations}

Orr G, WB Chrisler, KJ Cassens, R Tan, BJ Tarasevich, LM Markillie, RC Zangar, and BD Thrall. 2010. "Cellular Recognition and Trafficking of Anionic Nanoparticles by Macrophage Scavenger Receptor A." Society of Toxicology Annual Meeting and ToxExpo, Salt Lake City, UT. PNNLSA-70550.

Minard KR, BD Thrall, JG Teeguarden, MH Littke, VB Mikheev, and W Wang. 2010. "Magnetic Particle Detection (MPD) for Rapid Cell and Tissue Dosimetry." Society of Toxicology Annual Conference, Washington, DC. PNNL-SA-75603.

Jacob RE, BG Amidan, JJ Soelberg, KR Minard, and C Timchalk. 2010. "Application of Magnetic Resonance Imaging (MRI) for Non-Invasive Local Assessment of Acute and Chronic Lung Response ." Society of Toxicology Annual Conference, Salt Lake City, UT on March 8, 2010. PNNL-SA-71282.

Karin NJ, KM Waters, JG Teeguarden, W Wang, JA Price, RD Quesenberry, and BD Thrall. 2011. "Global Gene Profiling Reveals Dose and Time Progression of Key Biological Responses of Lung epithelial Cells to Nanoscale Amorphous Silica in Vitro." Society of Toxicology Annual Conference, Washington, DC. PNNL-SA-75456.

Waters KM, and NA Baker. 2011. "Meeting the Challenge of Nanomaterial Hazard Assessment with QSAR: Opportunities, Challenges and Successes." Society of Toxicology Annual Conference, San Francisco, CA. PNNL-SA-79836.

Karin NJ, MJ Gaffrey, MH Littke, KM Waters, JG Teeguarden, W Wang, JA Price, and BD Thrall. 2011. "Transcriptional Reprogramming of Lung Epithelial Cells by Low Dose Exposure to Silica Nanoparticles Leads to Enhanced Susceptibility to Metal Cytotoxicity." Society of Toxicology Annual Conference, San Francisco, CA. PNNL-SA-83234. 
Kodali VK, MH Littke, G Sharma, Y Xiong, KR Minard, and BD Thrall. 2011. "Role of Nanoparticle Surface Chemistry on Cellular Recognition and Uptake by Macrophage Scavenger Receptor-A." Society of Toxicology Annual Conference, San Francisco, CA. PNNL-SA-83301.

Teeguarden JG. 2011. "Enabling Prediction and Extrapolation: A New Paradigm for Nanomaterial Dosimetry In Vitro ." Presented by Justin Teeguarden at Society of Toxicology 2011, Washington DC, DC on March 7, 2011. PNNL-SA-80210.

\subsection{Invited Presentations}

Teeguarden JG, PM Hinderliter, BD Thrall, G Orr, KM Waters, RA Corley, and JG Pounds. 2010. "The Particokinetic and Physiological Basis for In Vitro-In Vivo Extrapolation of Nanomaterial Toxicity Studies. " Presented by Justin Teeguarden, Society of Toxicology Annual Conference, 2010, Salt Lake City, UT. PNNL-SA-68943.

Jacob RE. 2010. " The Role of In Vivo Imaging in Toxicological Studies." Presented by Richard Jacob, Symposium on "The Role of In Vivo Imaging in Toxicological Studies", Society of Toxicology Annual Conference, Salt Lake City, UT. PNNL-SA-70982.

Karin NJ, KM Waters, RD Quesenberry, MH Littke, W Wang, and BD Thrall. 2010. "In Vitro Effects of Engineered Nanomaterials on Biological Pathways." Presented by Katrina Waters at Fundamental \& Computational Sciences Directorate Review Committee Annual Meeting, Richland, WA on June 15, 2010. PNNL-SA-73704.

Teeguarden JG. 2010. "In Vitro Nanotoxicology: The Risk Assessor’s Little House of Horrors." Presented by Justin Teeguarden at Oregon Nanoscience and Nanotechnologies Institute Green Nano Meeting, Portland, OR. PNNL-SA-74302.

Teeguarden JG. 2010. "Physics, Physiology and Kinetics-The Foundation for Predictive Modeling of Nanomaterial Dosimetry for EHS Assessments." Presented by Justin Teeguarden (at National Academy of Sciences Committee on Environmental, Health, and Safety Reseach on Nanomaterials, Washington, DC. PNNL-SA-74303.

Thrall BD. 2010. "Systems-Level Approaches to Understanding Nanoparticle Biocompatibility." Presented by Brian D. Thrall at Pittcon Conference, Orlando, FL. PNNL-SA-75261.

Teeguarden JG. 2010. "Nanomaterial Dosimetry and Risk Assessment ." Presented by Justin Teeguarden, Washington State University, Richland Campus, WA. PNNL-SA-76619.

Teeguarden JG. 2011. "Enabling Prediction and Extrapolation: A New Paradigm for Nanomaterial Dosimetry In Vitro ." Presented by Justin Teeguarden at 2011 Toxicology and Risk Assessment Conference (TRAC), Cincinnati, OH on April 26, 2011. PNNL-SA-80211.

\subsection{Publications}

Orr, GA, WB Chrisler, KJ Cassens, R Tan, BJ Tarasevich, LM Markillie, RC Zangar and BD Thrall. 2011. "Cellular Recognition and Trafficking of Amorphous Silica Nanoparticles by Macrophage Scavenger Receptor A”. Nanotoxicology, 5(3):296-311 (doi: 10.3109/17435390.2010.513836) 
Hinderliter PM, KR Minard, G Orr, WB Chrisler, BD Thrall, JG Pounds, and JG Teeguarden. 2010. "ISDD: A Computational Model of Particle Sedimentation, Diffusion and Target Cell Dosimetry for In Vitro Toxicity Studies." Particle and Fibre Toxicology 7(November):Article No. 36. doi:10.1186/1743-8977-7-36

Hanns-Rudolf P, FR Cassee, JG Teeguarden, H Fissan, S Diabate, M Aufderheide, WG Kreyling, O Hanninen, G Kasper, M Riediker, B Rothen-Rutishauser, and O Schmid. 2011. "In-vitro Cell Exposure Studies for the Assessment of Nanoparticle Toxicity in the Lung - A Dialogue between Aerosol Science and Biology." Journal of Aerosol Science 42(10):668-692. doi:10.1016/j.jaerosci.2011.06.005

Karin, NJ, MJ Gaffrey, MH Littke, JG Teeguarden, KM Waters, W Wang, JA Price and BD Thrall. 2012. Transcriptional reprogramming of lung epithelial cells by low dose exposure to silica nanoparticles leads to enhanced susceptibility to metal cytotoxicity. In revision.

Minard, KR, MH Littke, W Wang, Y Xiong, JG Teeguarden, and BD Thrall. Magnetic Particle Detection (MPD) for In vitro Dosimetry”. Submitted, Biosensors and Bioelectronics.

Sharma, G, V Kodali, M Gaffrey, W Wang, KR Minard, NJ Karin, JG Teeguarden, and BD Thrall. 2012. "Iron Oxide Nanoparticle Agglomeration Influence Dose Rates and Modulates Oxidative Stress Mediated Dose Response Profiles In vitro”. Submitted, Nanotoxicology.

Teeguarden, JG, VB Mikeev, KR Minard, WC Forsythe, W Wang, G Sharma, N Karin, SC Tilton, KM Waters, B Ashgarian, OR Price, JG Pounds and BD Thrall. 2012. "Comparative Iron Oxide Nanoparticle Dosimetry and Response in Balb/c Mice by the Inhalation and Liquid Cell Culture Exposure Routes. Final draft for submission to Particle Fiber Toxicology.

Mikheev VB, WC Forsythe, KR Minard, and W Wang. 2012. "Generation and Characterization of Nano-Magnetosol Delivery to the Lungs ." In: Respiratory Drug Delivery 2012 Arizona. PNNL-SA85457 (in press).

\section{PNNL Subject Inventions Derived Under the CRADA}

One invention report was filed by PNNL as a result of this work and disclosed to Battelle and the other Lab Contractors on June 21, 2011:

- IPID 17114-E, “Multi-modal Approach for In Vivo Magnetic Particle Dosimetry”.

\section{References}

Hinderliter PM, KR Minard, G Orr, WB Chrisler, BD Thrall, JG Pounds, and JG Teeguarden. 2010. "ISDD: A Computational Model of Particle Sedimentation, Diffusion and Target Cell Dosimetry for In Vitro Toxicity Studies." Particle and Fibre Toxicology 7(November):Article No. 36.

Krause, HJ, N Wolters, Y Zhang, A Offenhausser, P Miethe, MHF Meyer, M Hartmann, and M Keusgen. 2007. Magnetic particle detection by frequency mixing for immunoassay applications. J. Mag. Magn. Mater. 311:436-444. 
Nikitin, PI, PM Vetoshko, and TI Ksenevich. 2007. New type of biosensor based on magnetic nanoparticle detection. J. Magn. Magn. Mater. 311(1):445-449.

Nikitin, MP, M Torno, H Chen, A Rosengart, and PI Nikitin. 2008. "Quantitative real-time in vivo detection of magnetic nanoparticles by their nonlinear magnetization.” J. Appl. Phys. 103(7).

Waters, KM, LM Masiello, RC Zangar, BJ Tarasevich, NJ Karin, RD Quesenberry, S Bandyopadhyay, JG Teeguarden, JG Pounds and BD Thrall. 2009. "Macrophage responses to silica nanoparticles are highly conserved across particle sizes." Toxicol. Sci. 107(2):553-569. 